\title{
Non-square open-loop dynamic model of methyl acetate production process by using reactive distillation column
}

\author{
Ahmad Misfa Kurniawan ${ }^{1}$, Renanto Handogo ${ }^{1, *}$, Hao-Yeh Lee $^{2}$, and Juwari Purwo Sutikno ${ }^{1}$ \\ ${ }^{1}$ Department of Chemical Engineering, Institut Teknologi Sepuluh Nopember, 60111 Surabaya, Indonesia \\ ${ }^{2}$ Department of Chemical Engineering, National Taiwan University of Science and Technology, 10607 Taipei, Taiwan
}

\begin{abstract}
The development of mathematics model especially non-square open-loop dynamic model has grown rapidly since four decades. Because of the need of simplicity and accuracy, industrial world is demanding a dynamic mathematical model as simple as possible but it still can represent the whole real process. Therefore, to meet those needs, an open-loop dynamic model of methyl acetate production process by using reactive distillation column has been built. Feed ratio, reflux ratio and reboiler duty were chosen to be the manipulated variables to make a better performance rather than only reflux flowrate and reboiler duty. Methyl acetate fraction in distillate and water fraction in bottom were still be selected as controlled variables, so a non-square open-loop dynamic model was formed.
\end{abstract}

\section{Introduction}

In the development of chemical industry on a large scale, it is necessary to understand the whole process behavior. This is an important issue because it can be used as a guidance to get the desired production result and to keep the operating conditions as safe as possible. The behavior of a process plant can be represented by the mathematical model of its process [1]. Therefore, the development of a mathematical model is very effective in the observation of industrial processes that have a large production scale [2]. There are many way to build a mathematic model of a process plant including derivation of mass and energy balance. In 1973, Wood and Berry introduced a mathematical model in the form of transfer function matrix of the distillation column. This matrix represents dynamic process of a distillation column in the form of 2x2 MIMO which has two controlled variables and two manipulated variables. Those two controlled variables are distillate fraction and bottom fraction. While those two manipulated variables are reflux ratio and steam flowrate [3]. Then in 1978, a $3 \times 3$ MIMO separation process between benzene and toluene by using a distillation column was proposed by Doukas and Luyben. Where there are three controlled variables of toluene fraction in bottom column, toluene fraction in top column, and benzene fraction in side draw. And there are three manipulated variables of reflux ratio, side draw flowrate, and reboiler duty [4]. Then in 1987, a non-square MIMO matrix was introduced by Prett and Morari. This mathematic model was referred to as shell standard control problem where it has two controlled variables and three manipulated variables [5]. Considering the importance of the development of the mathematical model, it is necessary to have a model as simple as possible to facilitate the simulation process but it can represent the reality of the process being modeled. In this paper, the development of mathematical model which can represent RDC (Reactive Distillation Column) process as a whole in the form of non-square MIMO with FOPTD (first order plus time delay) transfer function will be put forward.

\section{Process Description}

The process as shown in Figure 1 was suggested by Tang, et al. (2005) as the most sufficient and efficient configuration for production of methyl acetate by using reactive distillation column.[6] In reactive distillation column configuration, reaction and separation process are taking place only in one column. Rather than using reactor as reaction device and distillation column as separation device, reactive distillation configuration is more economic because it can minimize total annual cost compared to the conventional configuration [7].

\subsection{Production of Methyl Acetate by Using Reactive Distillation Column}

In this process, each reactant (methanol and acetic acid) are entering reactive distillation column in equimolar amount at the same temperature and pressure condition. Top product of that distillation column is methyl acetate with water and remaining reactant (methanol and acetic acid) as the impurities. Whereas the bottom product of the distillation column is containing water with a little bit of remaining reactant and methyl acetate [6].

\footnotetext{
* Corresponding author: renanto@,chem-eng.its.ac.id
} 


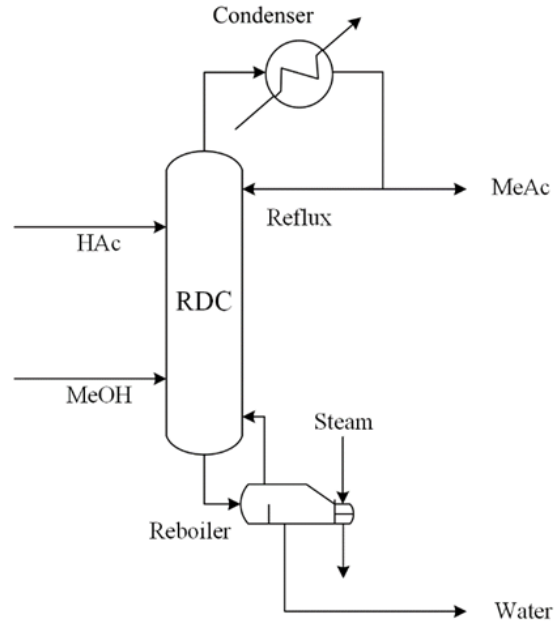

Fig. 1. Process scheme of the methyl acetate production.

Operating condition for the reactive distillation process are shown below:

- There are 38 total stage including condenser and reboiler.

- Column diameter is equal to 1.0327 meter.

- Reaction zone is in stage-3 until stage-36.

- First feed is pure acetic acid which is entering column at stage- 4 in the amount of $50 \mathrm{kmol} / \mathrm{hr}$ with 2 atm pressure as liquid.
- Second feed is pure methanol which is entering column at stage- 28 in the amount of $50 \mathrm{kmol} / \mathrm{hr}$ with 2 atm pressure as liquid.

- Top column pressure is equal to $1.1 \mathrm{~atm}$ and condenser pressure is equal to $1 \mathrm{~atm}$.

- The purity of the methyl acetate as top product of the distillation process has to greater than $98 \%$, while the purity of the water as bottom product of the distillation process has to greater than $98 \%$.

- Catalyst density is equal to $770 \mathrm{~kg} / \mathrm{m}^{3}$ with assumption of $50 \%$ reactive liquid hold up $\left(\mathrm{m}^{3}\right)$

It is known that reaction equation of methyl acetate is shown in equation (1).

$$
r=m_{c a t} k_{f} \alpha_{\mathrm{HAc}} \alpha_{\mathrm{MeOH}}-k_{r} \alpha_{\mathrm{MeAc}} \alpha_{\mathrm{H}_{2} \mathrm{O}}
$$

where,

$$
\begin{aligned}
& k_{f}=2.961 \times 10^{4} e^{\frac{-49190}{R T}}\left[\frac{\mathrm{kmol}}{\mathrm{kg} \cdot \mathrm{s}}\right] \\
& k_{r}=1.348 \times 10^{6} e^{\frac{-69230}{R T}}\left[\frac{\mathrm{kmol}}{\mathrm{kg} \cdot \mathrm{s}}\right]
\end{aligned}
$$

UNIQUAC thermodynamic model for methyl acetate production process is shown in Table 1 [6].

Table 1. UNIQUAC Thermodynamic Model for Esterification Process of Methyl Acetate.

\begin{tabular}{cllllll}
\hline $\begin{array}{l}\text { Comp. } \mathrm{i} \\
\begin{array}{l}\text { Comp. } \mathrm{j} \\
\text { Temperature } \\
\text { unit }\end{array}\end{array}$ & $\mathrm{HeOH}$ & $\mathrm{MeAc}$ & $\mathrm{HAc}$ & $\mathrm{MeOH}$ & $\mathrm{MeOH}$ & $\mathrm{MeAc}$ \\
\hline $\mathrm{H}_{2} \mathrm{O}$ & $\mathrm{K}$ & $\mathrm{K}$ & $\mathrm{K}$ & $\mathrm{K}$ & $\mathrm{K}$ & $\mathrm{K}$ \\
$\mathrm{a}_{\mathrm{ji}}$ & -0.97039 & 0.43637 & 0.051007 & 0.71011 & -3.1453 & -0.01014 \\
$\mathrm{~b}_{\mathrm{ij}}$ & 2.0346 & -1.1162 & 0.29355 & -0.72476 & 2.0585 & -0.96295 \\
$\mathrm{~b}_{\mathrm{ji}}$ & -390.26 & 62.186 & -422.38 & -62.972 & 575.68 & -593.7 \\
$\mathrm{c}_{\mathrm{ij}}$ & -65.245 & -81.848 & 98.12 & -326.2 & -219.04 & 265.83 \\
$\mathrm{c}_{\mathrm{ji}}$ & 0 & 0 & 0 & 0 & 0 & 0 \\
$\mathrm{~d}_{\mathrm{ij}}$ & 0 & 0 & 0 & 0 & 0 & 0 \\
$\mathrm{~d}_{\mathrm{ji}}$ & 0.003061 & -0.00027 & 0.00024 & -0.00117 & 0.006071 & 0.002161 \\
& -0.00316 & 0.001331 & $7.67 \mathrm{E}-05$ & 0.002355 & -0.00701 & -0.0002 \\
\hline
\end{tabular}

\section{Process Simulation}

Process simulation of reactive distillation column was built by using Aspen Plus 7.3. To get the mathematic model of its control system, dynamic conversion was needed so that the step test method can be applied to that control system. This step test method was based on the process reaction curve found by Ziegler and Nichols in 1942. A matrix of process transfer function can be found by using that method [8].
In the dynamic simulation built by using Aspen Plus Dynamic 7.3, two PI controllers had been placed to maintain condenser pressure and condenser level at certain value by manipulating condenser duty and distillate flowrate. These two controllers are in auto mode (closed-loop) to maintain the stability of the process while step test is taking place. Control scheme of methyl acetate production process during the step test is shown in Figure 2. 


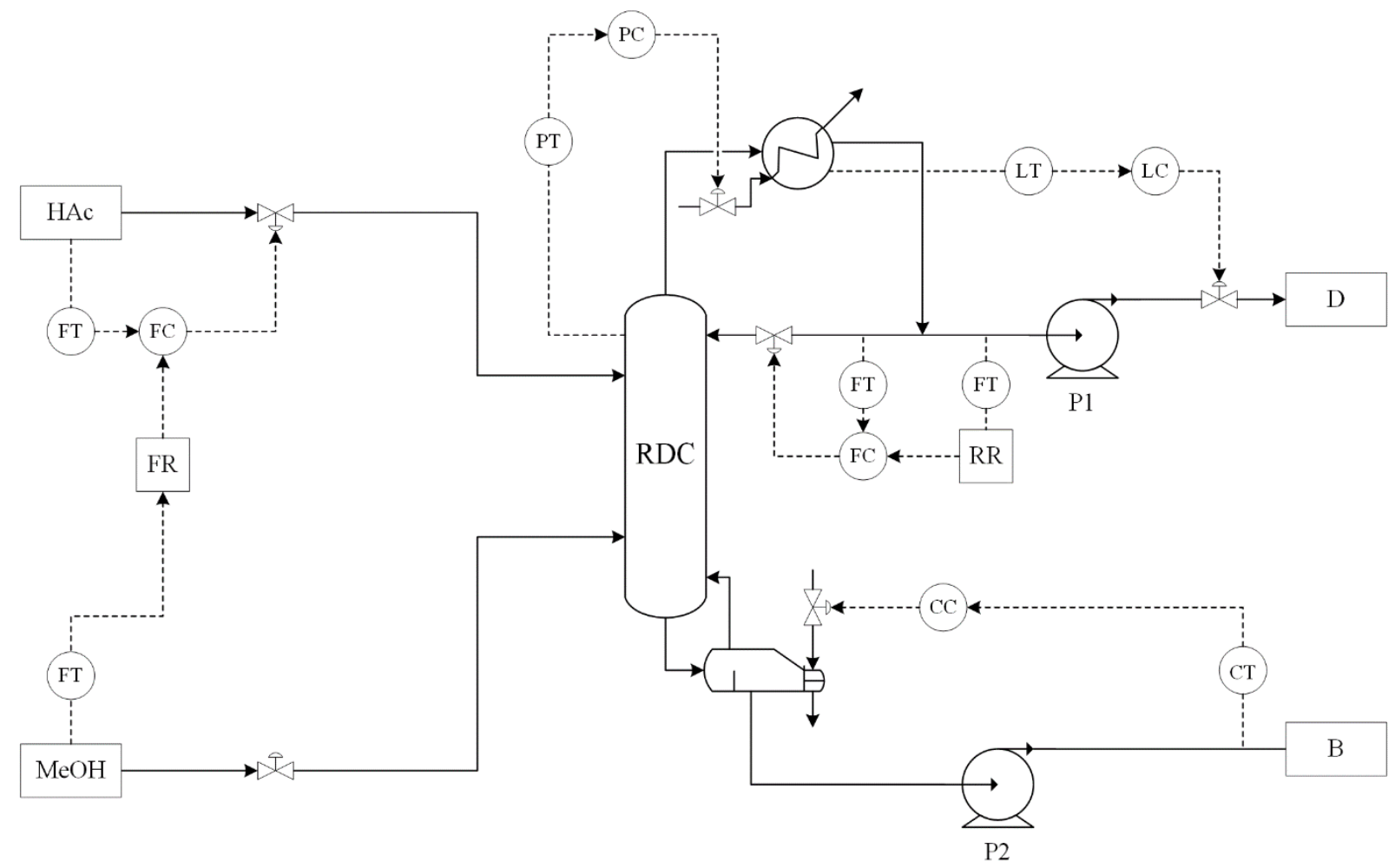

Fig. 2. Scheme of methyl acetate production process during the step test.

There are three manipulated variables of feed ratio (FR), reflux ratio (RR), and reboiler duty (QR) and two controlled variables of methyl acetate fraction in distillate $\left(\mathrm{X}_{\mathrm{D}}\right)$ and water fraction in bottom $\left(\mathrm{X}_{\mathrm{B}}\right)$. Those two controlled variables were chosen based on the requirement of product purity (methyl acetate in distillate) that has to be maintained equal or greater than $98 \%$ and water purity in bottom is maintained equal or greater than $98 \%$ too. Applying reflux ratio as a manipulated variable can be done by placing multiplier as a ratio station to adjust reflux flowrate with considering distillate flowrate. The magnitude of this multiplier is the reflux ratio its self. The next manipulated variable was reboiler duty. To adjust reboiler duty, a controller was used to connect water fraction in bottom as the controlled variable and reboiler duty as the manipulated variable. But, it was set in manual mode (open-loop) so that a disturbance changes can be given to reboiler duty manually. The last manipulated variable was feed ratio. This manipulated variable was chosen because ratio of acetic acid and methanol feed entering the column must be able to adapt to the reaction needs in the reactive distillation column.

\section{Step Test}

Step test was done by giving a step disturbance changes in one manipulated variable while maintaining the other manipulated variables constant and then recording response of all controlled variables from the beginning (when the disturbance is given) until a new steady state value of each controlled variables attained. This step was repeated to the other manipulated variables.

\subsection{Step Test Result}

Calculation based on graphical perusal was the method to determine every parameters of the process transfer function. To compensate error from the graphical perusal, aspen calculation was used to validate graphical method calculation. Response of every controlled variables on the changes of every manipulated variables can be shown in Figure 3.

\footnotetext{
* Corresponding author: renanto@,chem-eng.its.ac.id
} 


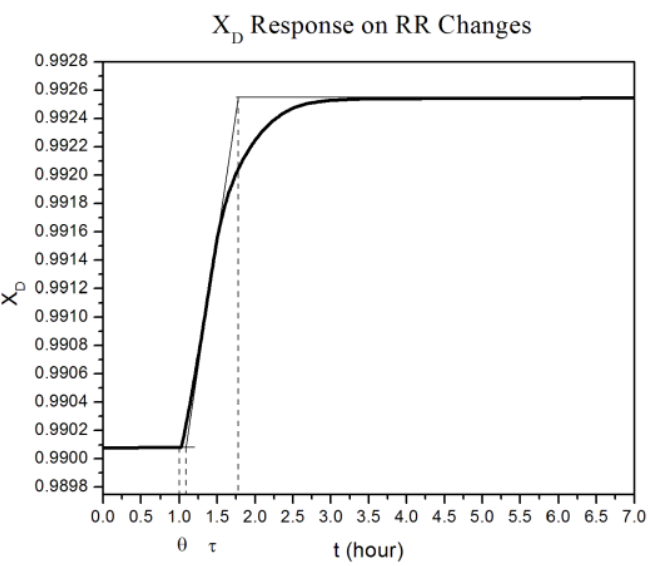

(a)

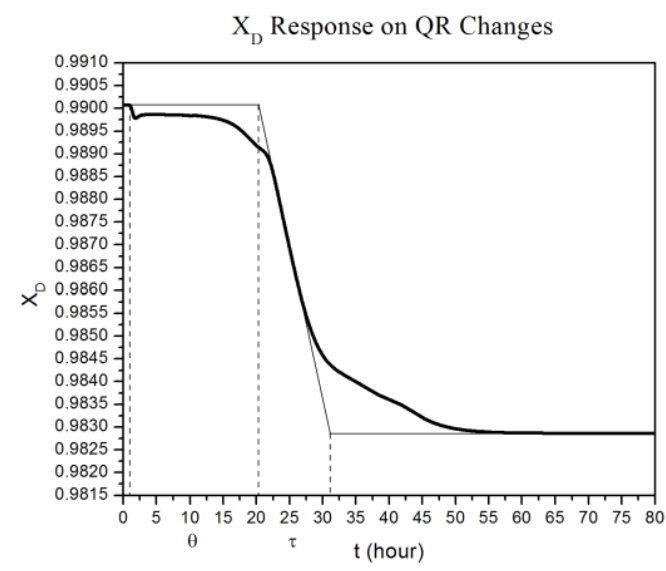

(c)

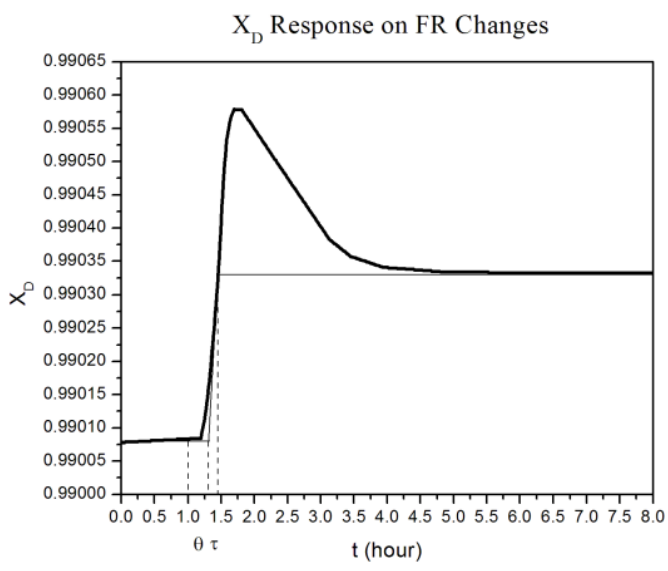

(e)

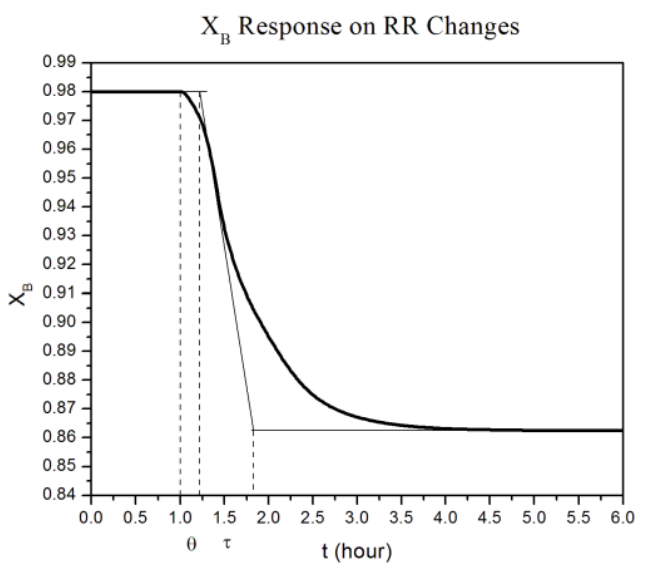

(b)

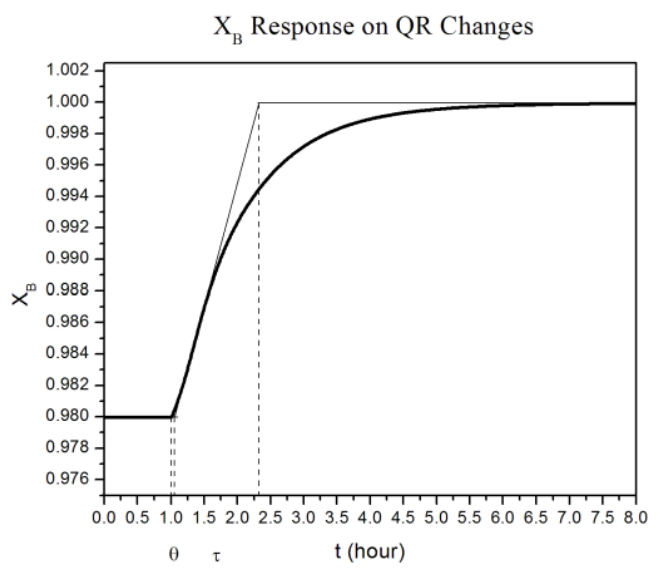

(d)

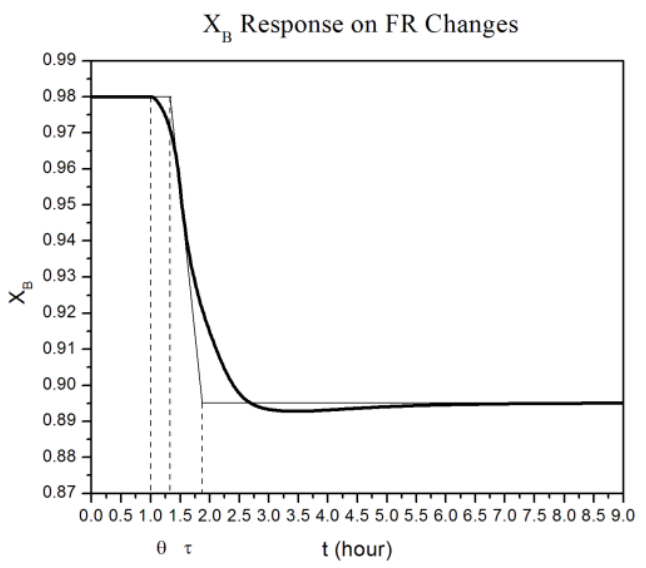

(f)

Fig. 3. Response from all controlled variables on the changes of every manipulated variables.

The first manipulated variable that was changed was reflux ratio. Magnitude of the reflux ratio was changed $10 \%$ from initial value. The initial reflux ratio was 1.98616 and then it was changed to 2.18478 after 1 hour. Figure 3.a and 3.b show $\mathrm{X}_{\mathrm{D}}$ and $\mathrm{X}_{\mathrm{B}}$ responses to the RR changes sequentially. Then, in the changes of reboiler duty as the second manipulated variables, reboiler duty was changed $2 \%$ from the initial value. The initial reboiler duty was $0.879685 \mathrm{MMkcal} / \mathrm{hr}$ and then it was changed to $0.897488 \mathrm{MMkcal} / \mathrm{hr}$ after 1 hour. Figure 3.c and 3.d show $\mathrm{X}_{\mathrm{D}}$ and $\mathrm{X}_{\mathrm{B}}$ responses to the QR changes sequentially. The last manipulated variable that was changed was feed ratio. Magnitude of the feed ratio was changed $10 \%$ from initial value. The initial feed ratio was 1 and then it was changed to 1.1 after 1 hour. Figure 3.e and 3.f show $X_{D}$ and $X_{B}$ responses to the FR changes sequentially. After recording all of the responses, graphical calculation based on the process reaction curve found by Ziegler and Nichols was done.[8] All parameters of process transfer function that were obtained from graphical calculation can be seen in Table 2 . To verify that value, 
a calculation utilized a toolbox from Aspen has been done. Those results can be seen in Table 3 .

It is shown from Table 3 that the graphical calculation only slightly different with Aspen calculation and it is tolerable. It should be noted that there is no delay caused from measuring element in the Aspen simulation process. The simplified open-loop dynamic model was expressed as shown in equation (2).

$$
\left[\begin{array}{l}
X_{D} \\
X_{B}
\end{array}\right]=\left[\begin{array}{ccc}
\frac{0.0249 e^{-0.07 s}}{0.7 s+1} & \frac{-0.3679 e^{-19.36 s}}{10.53 s+1} & \frac{0.0025 e^{-0.32 s}}{0.13 s+1} \\
\frac{-1.1867 e^{-0.23 s}}{0.62 s+1} & \frac{1.0185 e^{-0.05 s}}{1.27 s+1} & \frac{-0.8658 e^{-0.34 s}}{0.53 s+1}
\end{array}\right]\left[\begin{array}{c}
R R \\
Q R \\
F R
\end{array}\right]
$$

Table 2. All parameters of process transfer function obtained from graphical calculation.

\begin{tabular}{|c|c|c|c|c|c|c|c|c|c|}
\hline & \multicolumn{3}{|c|}{$\mathrm{RR}$} & \multicolumn{3}{|c|}{ QR } & \multicolumn{3}{|c|}{ FR } \\
\hline & $\mathrm{K}$ & $\tau$ & $\theta$ & $\mathrm{K}$ & $\tau$ & $\theta$ & $\mathrm{K}$ & $\tau$ & $\theta$ \\
\hline $\mathrm{X}_{\mathrm{D}}$ & 0.02474 & 0.69 & 0.09 & -0.36105 & 10.8 & 19.3 & 0.00254 & 0.14 & 0.31 \\
\hline$X_{B}$ & -1.17497 & 0.61 & 0.22 & 0.99805 & 1.27 & 0.05 & -0.84848 & 0.54 & 0.33 \\
\hline
\end{tabular}

Table 3. Comparison between Aspen and graphical calculation.

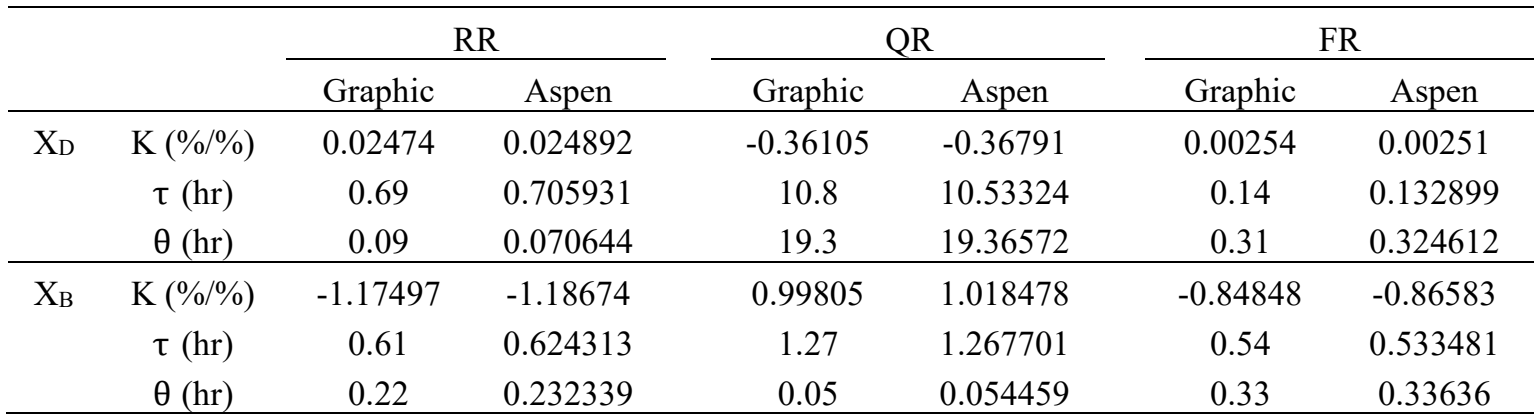

\section{Conclusion}

An open-loop dynamic model that represent methyl acetate production process by using reactive distillation column has been built based on process reaction curve of Ziegler and Nichols. The open-loop dynamic model as shown in Figure 2 is a $2 \times 3$ MIMO process containing a simple transfer function model FOPTD (first order plus time delay).

The authors would like to acknowledge the financial support of DIKTI - PMDSU research program on a contract of 003246.280/IT2.11/PN.08/2015 and PUPT (Penelitian Terapan Unggulan Perguruan Tinggi) Project No. 582/PKS/ITS/2017.

\section{References}

1. R. Aris, Chem. Eng. Sci. 46, 7 (1991)

2. S.S.E.H. Elnashaie, F.M. Alhabdan, Math. Comp. Mod. 17, 3 (1993)

3. R.K. Wood, M.W. Berry, Chem. Eng. Sci. 28, 1707-1717 (1973)

4. N. Doukas, W. Luyben, Anal. Instrum. 16, 51-58 (1978)

5. D.M. Prett, M. Morari, The Shell Process Control Workshop (Butterworths, Stoneham, USA, 1987)
6. Y.T. Tang, Y.W. Chen, H.P. Huang, C.C. Yu, AIChE J. 51, 6 (2005)

7. H.S. Fogler, Elements of Chemical Reaction Engineering $3^{\text {rd }}$ ed (Prentice Hall of India, India, 2004)

8. J.G. Ziegler, N.B. Nichols, Trans. of the ASME 64, 759-768 (1942) 